\title{
An Unusual Case of Carcinoma Ex-pleomorphic Adenoma of the Parotid Gland: A Comprehensive Clinicopathological Review
}

\author{
${ }^{1}$ PS Sharmila, ${ }^{2} \mathrm{~K}$ Shashikala, ${ }^{3} \mathrm{~K}$ Harish, ${ }^{4}$ Padmini Jeychandran
}

\begin{abstract}
Carcinoma ex-pleomorphic adenoma (CaxPA) is a carcinoma arising from a primary or recurrent benign pleomorphic adenoma (PA). It presents approximately $11.6 \%$ of all malignant neoplasms of salivary gland and mostly originates from major salivary glands. It is a common histologic subtype of primary parotid malignancy. Location in the minor salivary gland is uncommon and occurs in less than $7 \%$ of all cases. The majority of CaxPA develops from epithelial component of PA. Salivary gland tumors are known to have a benign clinical behavior with unrecognized metastatic potential. It often poses a diagnostic challenge to clinicians and pathologists. The entity is difficult to diagnose preoperatively. Pathologic assessment is the gold standard for making the diagnosis. We present a case of a 55 -year-old female patient who had a right preauricular mass of 10 years duration, with sudden onset of pain of duration of 1 month.
\end{abstract}

Keywords: Carcinoma ex-pleomorphic adenoma, Histopathology, Major salivary glands.

How to cite this article: Sharmila PS, Shashikala K, Harish K, Jeychandran P. An Unusual Case of Carcinoma Expleomorphic Adenoma of the Parotid Gland: A Comprehensive Clinicopathological Review. J Med Sci 2015;1(2):44-46.

Source of support: Nil

Conflict of interest: None

\section{INTRODUCTION}

Carcinoma ex-pleomorphic adenoma (CaxPA) is an infrequent aggressive malignancy, i.e. believed to evolve from a pre-existing benign pleomorphic adenoma. It accounts for $3.6 \%(0.9-14 \%)$ of all salivary neoplasms and for $11.7 \%$ (2.8-42.4\%) of salivary malignancies. ${ }^{1}$ The majority of CaxPA develops from epithelial component of PA. Carcinoma ex-pleomorphic adenoma is uncommon, as it has a prevalence rate of 5.6 cases per 100,000 malignant

\footnotetext{
${ }^{1,4}$ Professor, ${ }^{2}$ Assistant Professor, ${ }^{3}$ Consultant

1,2Department of Pathology, RajaRajeswari Medical College and Hospital, Bengaluru, Karnataka, India

${ }^{3,4}$ Department of Pathology, MVJ Medical College and Research Hospital, Bengaluru, Karnataka, India
}

Corresponding Author: PS Sharmila, Professor, 1174 Nagaraj Lay Out, Bull Temple Road, Bengaluru-19, Karnataka India, Phone: 9448473489, e-mail: ashwin.ashwin45@gmail. com neoplasms and a yearly incidence rate of 0.17 tumors per 1 million persons. Also, the disease is uncommon and often poses a diagnostic challenge to clinicians and pathologists. ${ }^{1}$ In this article, we have reviewed the recent literature and highlighted the current clinical, pathologic and molecular perspectives regarding this entity.

\section{CASE REPORT}

A 55-year-old female presented with a painless mass in the right preauricular region since 10 years. The mass had shown sudden rapid growth since 1 month and had become painful. Clinically, a diagnosis of salivary gland malignancy was made. The patient underwent right total parotidectomy, and the specimen was sent for histopathological analysis.

Grossly, the mass was well-circumscribed, partially encapsulated and firm measuring $6 \times 4 \times 2.5 \mathrm{~cm}$. The cut surface showed gray white lobulated appearance with foci of necrosis.

Microscopically, sections showed normal salivary gland, benign component of pleomorphic adenoma and malignant component exhibited round to oval epithelial cells with high nuclear cytoplasmic ratio, prominent nucleoli, abnormal mitoses (3-4/phf), nuclear pleomorphism, and necrosis with capsular, perineural, vascular and lymphatic invasion (Figs 1, 2 and 4). Few keratin pearls, extracellular and intracellular PAS +ve mucin in the cells (Fig. 3). The diagnosis of CaxPA with mucoepidermoid component was made.

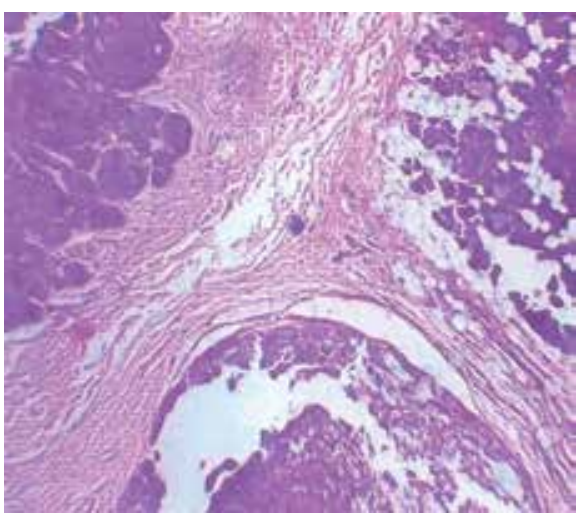

Fig. 1: Normal parotid gland with benign mixed and malignant tumor (H\&E: 40x) 


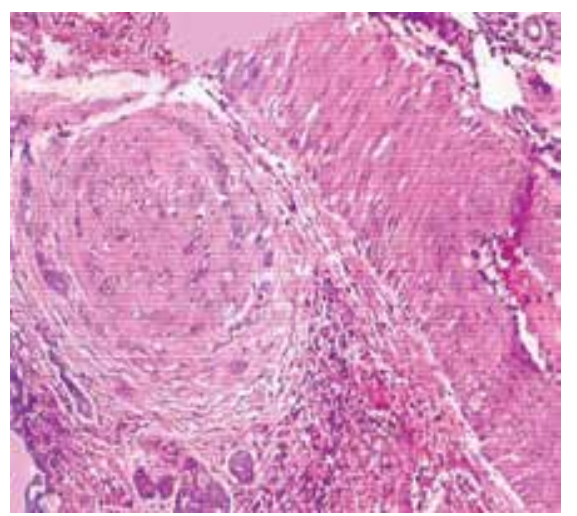

Fig. 2: Perineural invasion by malignant cells (H\&E: 40x)

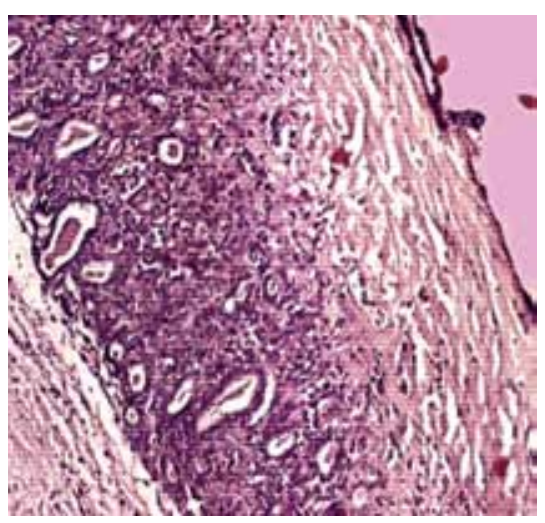

Fig. 4: Tumor cells showing capsular invasion (H\&E: 40x)

\section{DISCUSSION}

Carcinoma ex-pleomorphic adenoma represents approximately $11.6 \%$ of all malignant neoplasms of salivary gland and mostly originates from major salivary glands. ${ }^{1,2}$ Location in the minor salivary gland is uncommon and occurs in less than $7 \%$ of all cases. Carcinoma ex-pleomorphic adenoma predominantly affects the major salivary glands with a majority of cases noted in the parotid and submandibular glands. The cancer is known to manifest in the minor salivary glands in the oral cavity, particularly the hard and soft palates. In addition to these sites, cases of CaxPA have been reported in the breast, lacrimal gland, trachea, and nasal cavity. ${ }^{2,3}$ The majority of CaxPA develops from epithelial component of PA. Carcinoma ex-pleomorphic adenoma has been named as carcinoma ex-mixed tumor, carcinoma ex-adenoma, and carcinoma ex-benign pleomorphic adenoma. ${ }^{1}$ The current definition of CaxPA became widely accepted in the second half of the 20th century. It has a prevalence rate of 5.6 cases per 100,000 malignant neoplasms and a yearly incidence rate of 0.17 tumors per 1 million persons. Salivary gland tumors are known to have a benign clinical behavior with unrecognized metastatic potential. According to the World Health Organization (WHO), histological classification published in 2005,

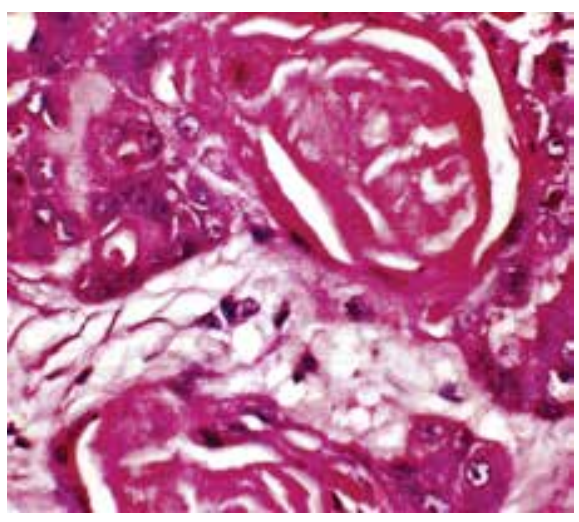

Fig. 3: PAS +ve keratin pearl component of epidermal carcinoma (PAS: 40x)

malignant changes in the PA include three different types: CaxPA, carcinosarcoma and metastasizing PA. ${ }^{1,3}$ The cancer is found predominantly in the 6th to 8 th decades of life and is slightly more common in females. The clinical presentation of CaxPA may be similar to that of PAs and the most common symptom was an asymptomatic mass and sometimes there is a longstanding history of PA. About $30 \%$ of patients present symptoms and signs including pain, facial nerve palsy, enlarged lymph nodes, skin ulceration and dysphasia. ${ }^{3}$ The time from onset of symptoms until diagnosis varied from 1 month to 52 years. The malignant component of CaxPA is most often adenocarcinoma not otherwise specified. Sometimes, the component may be adenoid cystic carcinoma, mucoepidermoid carcinoma or salivary duct carcinoma. ${ }^{3,4}$ The other less common histological subtypes include acinic cell carcinoma, epithelial-myoepithelial carcinoma, basal cell carcinoma, myoepithelial carcinoma, squamous cell carcinoma and clear cell carcinoma. ${ }^{4}$ The malignant component may also be a mixture of subtypes. Our case had benign component with mucoepidermoid differentiation. Fine needle aspiration cytology is commonly used preoperatively to diagnose benign component with CaxPA. The sensitivity, however, is low largely related to sampling error. ${ }^{5}$

Molecular studies have revealed that the development of CaxPA follows a multistep model of carcinogenesis, with the progressive loss of heterozygosity at chromosomal arms $8 q$, then $12 q$ and finally $17 p 3$. The concept of noninvasive CaxPA was first introduced in 1977 by LiVolsi and Perzin. Based on the presence and extent of invasion of the carcinomatous component outside the fibrous capsule, CaxPA can be subdivided into noninvasive CaxPA, minimally invasive CaxPA, and invasive CaxPA. Olsen et al noted that the extent of invasion beyond the fibrous capsule ranged from 2 to $100 \mathrm{~mm}$ with a mean of $24 \mathrm{~mm}^{3}$. When the malignant component of CaxPA undergoes $<1.5 \mathrm{~mm}$ penetration into extracapsular tissue, 
it is classified as minimally invasive, CaxPA invasive. CaxPA is defined as greater than $1.5 \mathrm{~mm}$ invasion by the malignant component from the tumor capsule into adjacent tissue. ${ }^{3}$ In our case, the tumor had perineural, vascular and lymphatic invasion.

\section{Prognosis}

Carcinoma ex-pleomorphic adenoma depends on pathological staging parameters like the level of invasion, lymph node involvement, and local or distant metastasis. Patients with high-grade carcinomatous components have poor prognosis when compared to patients with low-grade carcinomatous components. ${ }^{1,3,5}$

\section{CONCLUSION}

Carcinoma ex-pleomorphic adenoma is an uncommon entity with significant clinical and pathological relevance. It is important to be aware of the disease as it is difficult to be diagnosed both clinically and pathologically. While good locoregional disease control could be achieved with surgery and radiotherapy, carcinoma in pleomorphic salivary adenoma was shown to be aggressive with a high disease-specific rate of mortality.

\section{REFERENCES}

1. Kanematsu HK, Mizuta K, Ito Y, Hirose Y. Carcinoma ex-pleomorphic adenoma of the parotid gland: radiologicpathologic correlation with MR imaging including diffusion-weighted imaging. Head \& Neck Case Report. Am J Neuroradiol 2008 May;29(5):865-867.

2. Patil S, Gadbail AR, Chaudhary M. Carcinoma expleomorphic adenoma of parotid gland: clinicopathological and immunohistochemical study of a case. Oral Surg 2009; 2(4):182-187.

3. Antony J, Gopalan V, Smith RA, Lam AKY. Carcinoma expleomorphic adenoma: a comprehensive review of clinical, pathological and molecular data. Head Neck Pathol 2012 Mar;6(1):1-9.

4. Nouraei SA, Hope KL, Kelly CG, McLean NR, Soames JV. Carcinoma ex benign pleomorphic adenoma of the parotid gland. Plast Reconstr Surg 2005 Oct;116(5):1206-1213.

5. Papa F, Sagliocco R, Cosimo O, Russo A, Claudio PP, Errico M, Lavorgna G. Consideration on a case of carcinoma ex-pleomorphic adenoma of the parotid gland. Minerva Stomatol 1997 Nov;46(11):615-620. 